\title{
Brachymorphism-onychodysplasia-dysphalangism syndrome
}

\author{
Alain Verloes, Dominique Bonneau, Ornella Guidi, Michel Berthier, Denis Oriot, \\ Lionel Van Maldergem, Lucien Koulischer
}

\begin{abstract}
Three unrelated children are reported with intrauterine proportionate growth retardation and facial dysmorphism (broad nose, flat malar area, large mouth, pointed chin), microcephaly, hypo/aplasia of the terminal fifth digits, and (sub)normal intelligence. Radiological findings include hypo/aplasia or fusion of the distal phalanges of the fifth finger and toe, brachymesophalangism $V$, and nail dysplasia or aplasia. One child had cystic adenomatoid disease of the lung. The pattern of anomalies presented by these children closely resembles a syndrome incompletely delineated in 1971 by Senior in six children, which has often been considered to be a mild form of Coffin-Siris syndrome. We suggest that this is an independent entity (BOD syndrome). The aetiology is still unknown. Differential diagnosis and nosological difficulties are discussed.

( 7 Med Genet 1993;30:158-61)
\end{abstract}

In 1971, Senior' $^{1}$ described six 'short children with tiny toenails'. Pre- and postnatal short stature, hypoplastic fifth digits with abnormal phalanges and tiny toenails, facial dysmorphism, and, in some, mild intellectual impairment were observed. Except for a single report, ${ }^{2}$ no other cases have been recorded. We describe here three unrelated children fitting the 'Senior syndrome'.

Centre for Huma

University, Belgium.

A Verloes

L Koulischer

Department of Medical Genetics,

University Hospital,

Poitiers, France.

D Bonneau

M Berthier

D Oriot

\section{Department of}

Pediatrics, La

Citadelle Hospital,

Liège, Belgium.

$O$ Guidi

Institute for

Morphologic

Pathology, Loverval,

Belgium.

L Van Maldergem

Correspondence to Dr Verloes, Centre de Génétique, CHU Sart Tilman, B-4000 Liège Belgium.

Received 24 March 1992 Revised version accepted 18 June 1992. with a broad base, flattened malar are truding lips, and pointed chin (fig 1A,B). She had bilateral aplasia of the distal phalanges of the fifth digits (fig 1C), which had no nail. The fifth toes were very hypoplastic and lacked nails (fig 1D). The nails of the second, third, and fourth toes were small, dysplastic, and soft. Radiologically, the acral anomalies were restricted to the fifth digits and included minute terminal phalanges with probable symphalangism $2-3$ in the right hand (fig $2 \mathrm{~A}$ ), aplasia of P3 on the left, aplasia of P2 and P3 bilaterally in the fifth toes, and a single, short distal phalanx in toes 4 and 5 (fig 2B). Other radiological anomalies were partial fusion of L5 and the sacrum and large sella turcica (fig 2C). Brain CT scan was normal. There was no pituitary dysfunction and no visceral malformations. $\mathrm{G}$ banded karyotype was normal.

The family history is unremarkable. Her parents were tall and had normal head circumferences. They were aged 30 and 29 at the birth of the proband. She had two unaffected sibs.

CASE 2

This boy born at 39 weeks weighed $2400 \mathrm{~g}$ $(<10$ th centile) and had a birth length of $45 \mathrm{~cm}$ (10th centile). The pregnancy was uneventful and there was no exposure to drugs or teratogens. A cystic adenomatoid malformation of the lung was surgically removed at 1 month. Subsequent development was normal and not delayed. When evaluated at 2 years 5 months, he was $84 \mathrm{~cm}$ tall $(-2 \mathrm{SD})$, weighed $9750 \mathrm{~g}$, and had a head circumference of $47.5 \mathrm{~cm}(<-2 \mathrm{SD}) . \mathrm{He}$ had a flat, oval facies (fig 3A), with a high forehead, horizontal palpebral fissures, epicanthus, broad nasal root, flat malar area, upturned nose (fig 3B), long, smooth philtrum, high arched palate, and small, somewhat receding, pointed chin. The hands were stubby, with hypoplastic fifth nails, clinodactyly V, and bilateral transverse palmar creases. The left fifth nail was absent and the left fourth and right fifth nails were very hypoplastic. Radiographic investigations showed short distal phalanges in the fifth fingers (fig 4A) and absence of ossification of the median and distal phalanges of the fifth toes (fig 4B). On the left, the third phalanx of the fifth finger and toe was absent and only one ossification centre was visible in the left second and fourth toes. No other anomalies of the bones were recorded, except for two parietal lacunae (fig 4C). No visceral malformation was present. The karyotype was normal.

The family history was unremarkable. The father was $180 \mathrm{~cm}$ and the mother $163 \mathrm{~cm}$ tall They were not consanguineous. An older child was in good health. 

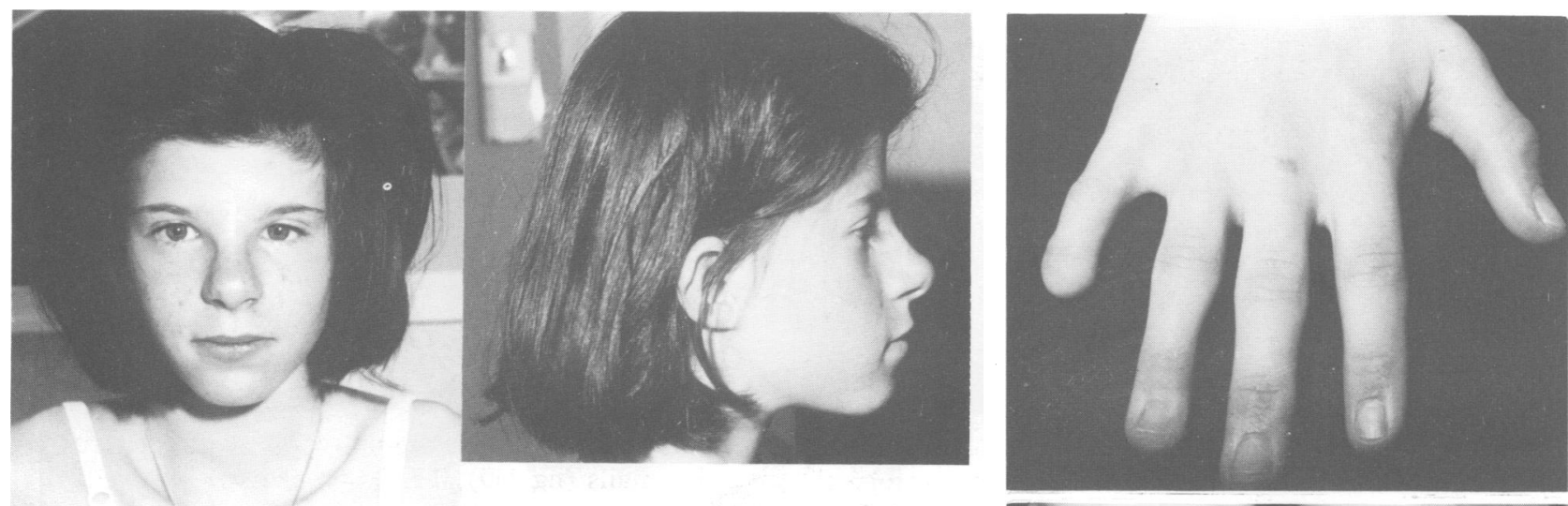

(A)

(B)

Figure 1 Patient 1 aged 14 years.

(A) Distinctive facies,

(B) profile: note brachycephaly,

(C) right hand,

(D) right foot.

(D)

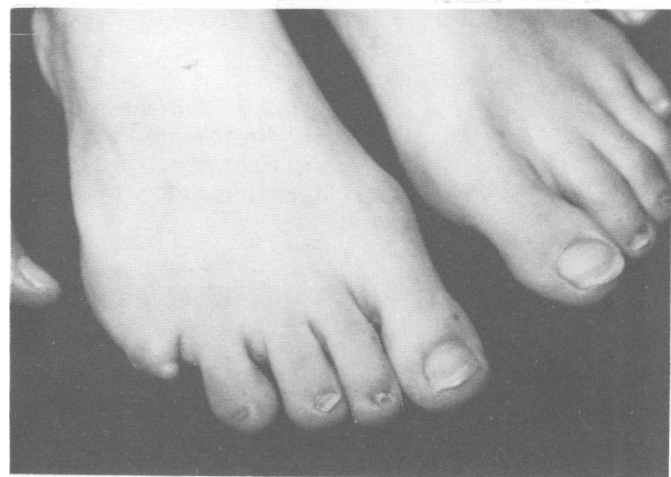

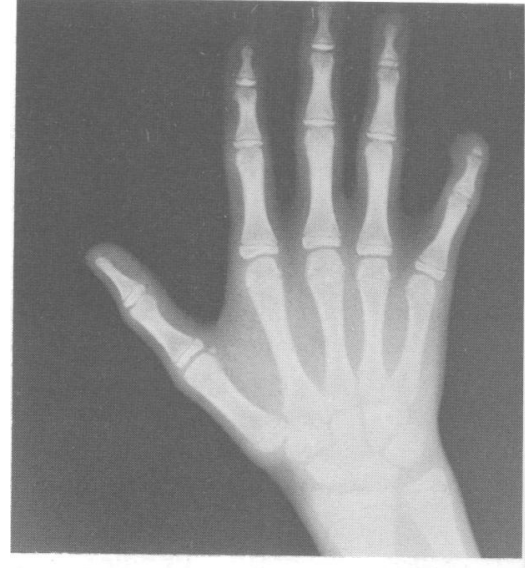

(A)

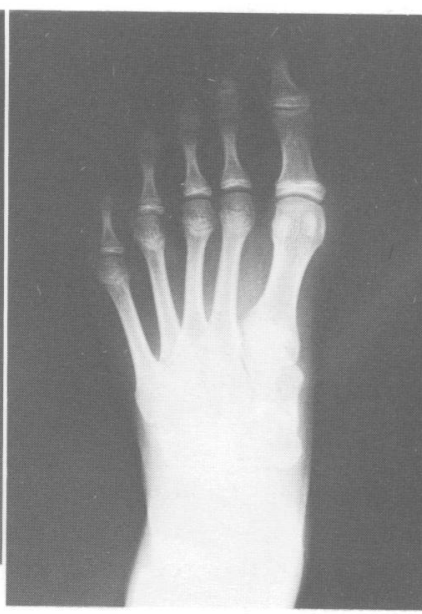

$(B$

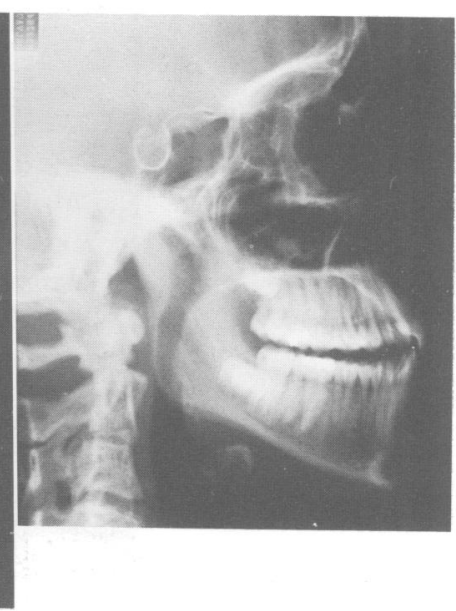

(C)

Figure 2 Patient 1. (A) X ray of right hand, (B) left foot, (C) large, round sella turcica.
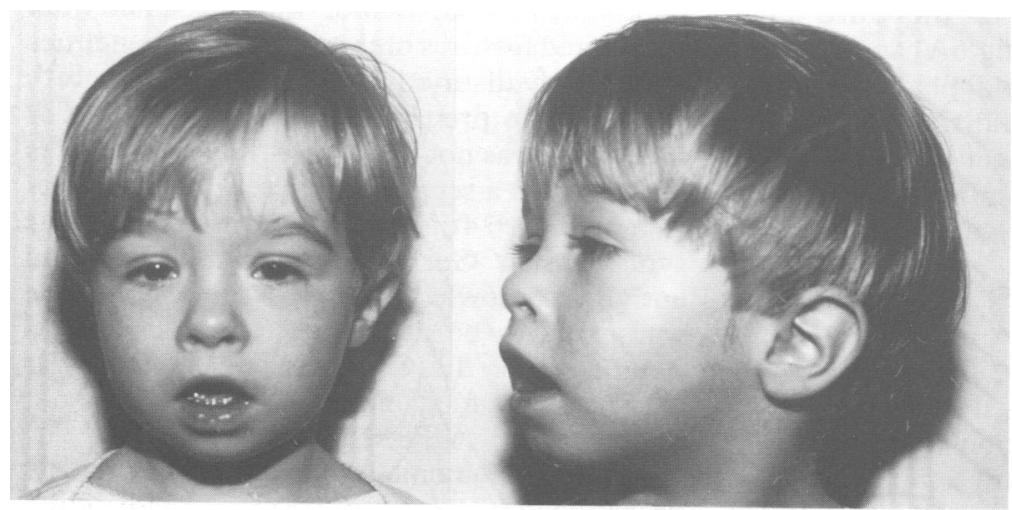

Figure 3 Patient 2 aged 30 months.
CASE 3

This girl was born at 34 weeks of gestation. The pregnancy was normal and there was no exposure to known teratogens. Birth weight was $1730 \mathrm{~g}$ (10th to 25 th centile) and birth length was $41 \mathrm{~cm}$ (10th centile) with a head circumference of $31.3 \mathrm{~cm}$ (mean). An ASD ostium secundum type was noted at birth. At 14 months, her mental development was normal. She was $66 \mathrm{~cm}$ tall ( $-3.5 \mathrm{SD})$, weighed $7200 \mathrm{~g}$, and had a head circumference of $43 \mathrm{~cm}$ $(-2.5 \mathrm{SD})$. She had a rounded facies with a pointed chin, upward slanting palpebral fissures, broad nasal root, epicanthus, large nose, and a long philtrum (fig 5). The distal phalanx of the left fifth finger was absent. The left third and fourth and the right fifth fingernails were hypoplastic, soft, concave, and thickened. The fifth toenails were hypoplastic bilaterally, as 


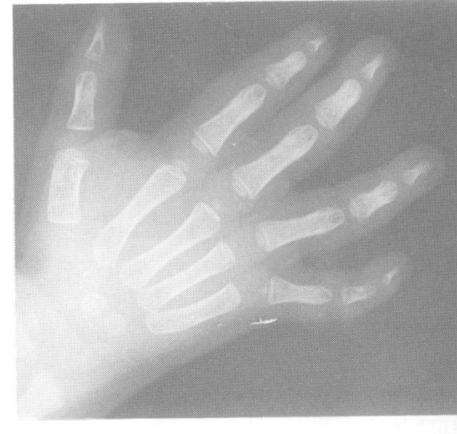

(A)

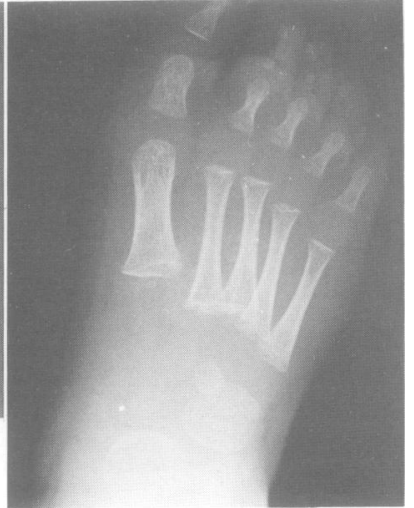

(B)

Figure 4 Patient 2.

(A) Right hand,

(B) right foot,

(C) skull: note prominent foramina.

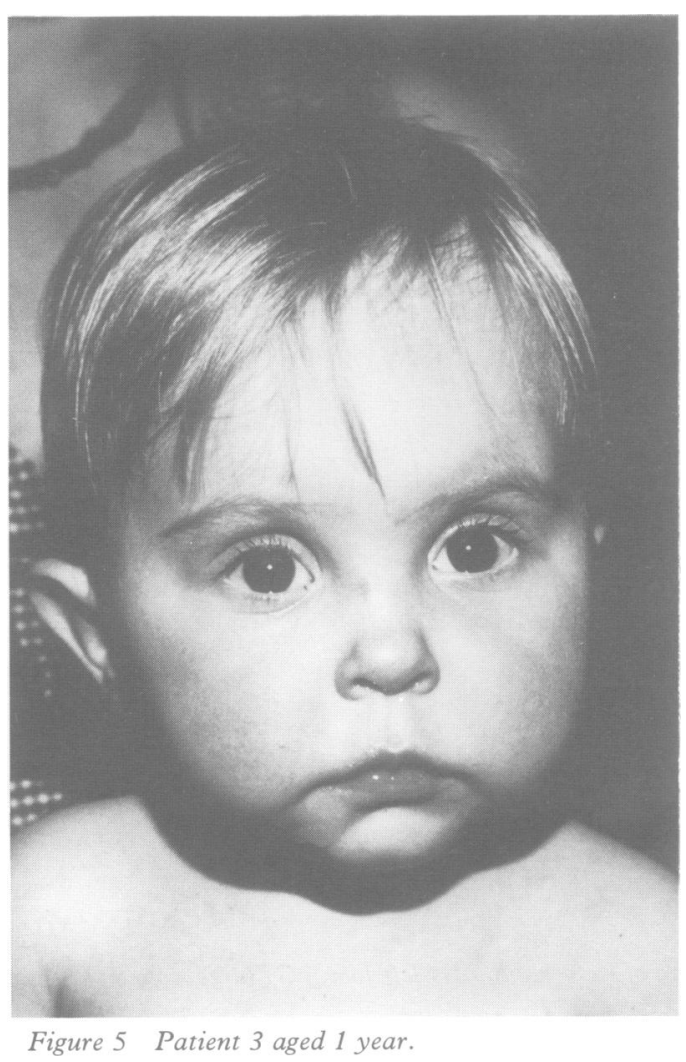

were the left third and fourth toenails. $X$ rays showed bilateral absence of the third phalanges in the fifth fingers (fig 6A) and absence of ossification of the two distal phalanges of the fifth toes (fig 6B). Family history was unremarkable. The mother, aged 34, was short $(160 \mathrm{~cm})$, as were her own mother and sisters. The father, aged 25, was $168 \mathrm{~cm}$ tall. They had no other children.

\section{Discussion}

Senior, ${ }^{1}$ in 1971 , reported six unrelated children with growth retardation (below the 3rd centile), peculiar facies, and acral anomalies. Five of them presented with absent $(1 / 5)$ or fused $(4 / 5)$ middle and distal phalanges and short fifth fingers, with brachyphalangism more pronounced in the middle ones. The sixth child was less convincing, as he had only tiny toenails. No information was given regarding prenatal exposure to drugs or microcephaly. Mace and Gotlin ${ }^{2}$ suggested the same diagnosis for a case with brachymetatarsia IV. The hand of another child with absent third phalanx was depicted in Poznanski's textbook. $^{3}$

The three children reported here show a concordant pattern of anomalies of the extremities and general growth failure, which fits the description of Senior. ${ }^{1}$ Brachydactyly is of the B type. ${ }^{4}$ The face has a similar triangular or oval shape with pointed chin and apparently large mouth (in patients 1 and 2). Absolute or relative microcephaly, an important feature in our cases, was not mentioned by Senior. ${ }^{1}$ Cystic malformation of the lung is a sporadic developmental anomaly, which could be fortuitous in case 2 . Children with the syndrome are of low normal intelligence or even slightly mentally impaired, as seen in patient 1 . Patients 2 and 3 are too young to determine moderate mental disturbance. The aetiology of Senior syndrome is not known and all cases were sporadic. The nine cases with available family data had 25 unaffected sibs. Consanguinity between parents has not been reported.

The delineation, and even the existence, of Senior syndrome remain controversial, particularly as the original cases were relatively poorly described. Senior himself stated that "the listed features of these patients are neither particularly distinctive, nor individually rare", and possible prenatal exposure to alcohol or phenytoin was not discussed. The syndrome is presented as a separate entry in two textbooks of radiology. ${ }^{35}$ It is discussed with Coffin-Siris syndrome in Gorlin's monograph ${ }^{6}$ (but the authors acknowledged that Senior syndrome was likely to be different). Senior's paper is quoted under the Coffin-Siris heading in the McKusick catalog 7 and in LDDB. It is not included in POSSUM.

The digital anomalies correspond to type B brachydactyly (apical dystrophy), ${ }^{4}$ which can include symphalangism and nail hypoplasia, 


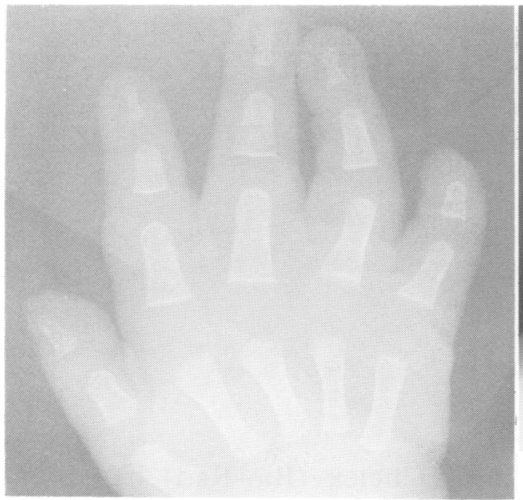

( A

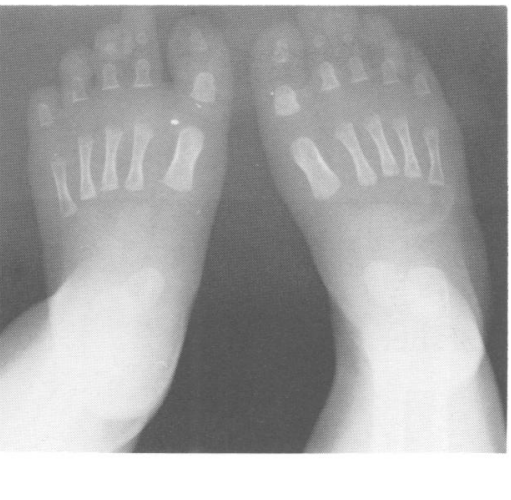

(B)

Figure 6 Patient 3 at birth. (A) Right hand, (B) feet.

and usually has a dominant mode of inheritance. However, it differs from the 'common' apical dystrophy by an unusual gradient of severity from the preaxial to the postaxial rays. Growth retardation and low intelligence are not associated with this type of brachydactyly. ${ }^{8}$ Around 50 syndromes may be extracted from LDDB or POSSUM, using a combination of ungual dysplasia/hypoplasia/aplasia, hypoplasia/aplasia of phalanges or terminal hypoplasia of fingers. In relation to Senior syndrome, most of them are easily rejected, because of their associated features (for example, Fryns syndrome and several ectodermal dysplasias). Ungual hypoplasia/dysplasia occurs in a form of brachydactyly classified as A4 by Poznanski ${ }^{3}$ or A5 by McKusick ${ }^{7}$ (autosomal dominant absence of middle phalanges with duplication of the terminal phalanx of the thumb $\left.{ }^{9}\right)$. Apical dystrophy has been observed in association with coloboma in Sorsby syndrome. ${ }^{1011}$ Schott $^{12}$ reported a dominantly inherited syndrome of hypo/aplasia of the terminal phalanges, sparing the thumb, associated with nail dysplasia. The feet were not affected. Goldshkag-Cooks et al ${ }^{13}$ reported nail dystrophy and terminal hypoplasia of the toes and fifth fingers in a two generation family. Some affected patients had triphalangeal thumbs. Ballard syndrome consists of camptodactyly, finger-like thumbs, distal phalangeal hypoplasia, nail dysplasia, and brachymetacarpia. ${ }^{14}$ None of these syndromes are associated with short stature, microcephaly, or mental subnormality. Our patients do not appear similar enough to be considered as having one of these syndromes. Fetal hydantoin syndrome may show terminal hypoplasia and growth retardation, but the facial features are different and no exposure to anticonvulsivant drugs was noted (at least in our cases). Dup(9p) syndrome shows the same acral anomalies but

severe mental impairment is a constant feature and chromosomes were normal in our patients 1 and 2.

Distal digital hypoplasia of the fifth ray is a hallmark of Coffin-Siris syndrome. This recessively inherited disease is characterised by microcephaly, growth retardation, constant, and usually severe, mental retardation with hypotonia, dorsal hirsutism, alopecia, patellar hypoplasia, and coarse facial features. ${ }^{6} \mathrm{Al}-$ though considering Senior syndrome as the mildest form of this syndrome cannot be rejected, it is difficult to combine in a single entity our mildly affected patients and the 'common' cases of Coffin-Siris syndrome. At least for clinical and prognostic reasons, the splitting of both entities seems reasonable.

At the moment, this syndrome seems best characterised as a recurrent pattern of anomalies of unknown genesis, ${ }^{15}$ with some similarities to Coffin-Siris syndrome, but distinguishable by a milder phenotype and much less severe mental handicap. Aetiological heterogeneity among the cases reported by Senior cannot be ruled out, or that some of them may in fact belong to one of the previously discussed syndromes. Nevertheless, we suggest that our cases (and at least some of those described by Senior) represent a genuine and clinically distinguishable entity. We would recommend the use of 'Brachymorphism-onychodysplasiadysphalangism (BOD) syndrome' to refer to it, rather than the eponymous 'Senior syndrome', to prevent confusion with the Senior-Loken syndrome.

1 Senior B. Impaired growth and onychodysplasia. Short children with tiny toenails. Am f Dis Child 1971;122:7-9.

2 Mace JW, Gotlin RW. Short stature and onychodysplasia. Report of a case resembling Senior syndrome. Am $\mathcal{J} D$ is Child 1973;125:114-6.

3 Poznanski AK. The hand in radiologic diagnosis. Philadelphia: Saunders, 1984.

4 Fitch N. Classification and identification of inherited brachydactylies. $\mathcal{F}$ Med Genet 1979;16:36-44.

5 Taybi H, Lachman RS. Radiology of syndromes, metabolic Taybi $\mathrm{H}$, Lachman RS. Radiology of syndromes, metabolic
disorders, and skeletal dysplasias. 3rd ed. Chicago: Year Book Medical Publishers, 1990.

6 Gorlin RJ, Cohen MM Jr, Levin LS. Syndromes of the head and neck. New York: Oxford University Press, 1990

7 McKusick VA, Francomano CA, Antonarakis SE. Mendelian inheritance in man. Catalogs of autosomal dominant, autosomal recessive, and $X$-linked phenotypes. 9th ed. Baltimore: Johns Hopkins University Press, 1990.

8 Temtamy S, McKusick V. The genetics of hand malformations. Birth Defects 1978;XIV(3):187-299.

9 Bass HN. Familial absence of middle phalanges with nail dysplasia: a new syndrome. Pediatrics 1968;42:318-23.

10 Phillips CI, Griffiths DL. Macular coloboma and skeletal abnormality. Br f Ophthalmol 1969;53:246-9.

11 Thompson EM, Baraitser M. Sorsby syndrome: a report on further generations of the original family. $\mathcal{f}$ Med Genet 1988;25:313-21.

12 Schott GD. Hereditary brachydactyly with nail dysplasia. $\mathcal{F}$ Med Genet reditary brachyd

13 Goldshkag-Cooks RG, Hertz M, Katznelson MBM. A new nail dysplasia syndrome with onychonychia and absence and/or hypoplasia of distal phalanges. Clin Genet 1985;27:85-91

14 Kumar D, Levick RK. Autosomal dominant onychodystrophy and anonychia with type B brachydactyly and ectrodactyly. Clin Genet 1986;30:219-25.

15 Cohen MM Jr. The child with multiple birth defects. New York: Raven Press, 1982. 